\title{
Família Curitibana: uma metodologia do trabalho com famílias
}

\author{
Curitiba family: a methodology of working with families
}

\author{
Rosely Aparecida Bittencourt* \\ Maria de Lourdes Corres Perez Sanroman ${ }^{* *}$
}

\begin{abstract}
Resumo:
O Projeto Família Curitibana, desenvolvido na Prefeitura Municipal de Curitiba (PMC), por meio da Fundação de Ação Social (FAS), é uma metodologia de trabalho com famílias em situação de vulnerabilidade social, traduzida em uma estratégia de abordagem técnica a um amplo conjunto de ações intersetoriais, das Políticas Sociais, como mecanismo de Proteção Social, reconhecido como Direito do Cidadão. A Proteção Social Pública por meio do Projeto em tela volta-se àquelas pessoas e famílias que vivem em condições de vulnerabilidade e risco social, pautando-se em uma visão de participação e atuação protagonista das famílias, rumo à autonomia e emancipação. O objetivo deste artigo é analisar o trabalho realizado com famílias no "Projeto Família Curitibana", segundo diretrizes e preceitos da Assistência Social, sistematizando-o e relacionando-o com metas intersetoriais de diferentes políticas públicas. O método empregado para coleta de dados é o da pesquisa documental, com consulta ao Protocolo de Gestão dos Centros de Referência da Assistência Social de Curitiba (CRAS), Protocolo de Gestão Intersetorial, Plano de Governo, relatórios Institucionais e de Avaliação do Projeto Família Curitibana. Para o Projeto foi estabelecido em Contrato de Gestão o atendimento a 7000 famílias entre 2009-2012, meta com tendência de atendimento integral no período. $O$ Projeto já aponta resultados positivos, tanto quantitativos quanto qualitativos, no âmbito da proteção social às famílias, com redução das vulnerabilidades sociais, ou no âmbito da gestão, com a ampliação do monitoramento e controle destas.
\end{abstract}

Palavras-chave: Metodologia do trabalho com famílias. Projeto família curitibana. Proteção social. Vulnerabilidade social.

\begin{abstract}
:
The Family Project Curitiba, developed in the Municipality of Curitiba (PMC), through the Social Action Foundation is a methodology of work with socially vulnerable families, translated into a strategy of technical approach to a wide range intersectoral action for Social Policy and Social Protection mechanism, recognized as the Citizen's Law. Social Protection Public through Project turns itself
\end{abstract}

\footnotetext{
*Assistente Social, Supervisora Regional da Fundação de Ação Social, Prefeitura Municipal de Curitiba, Mestre em Educação pela UEPG, Doutora em Educação pela UDE-Uy. E-mail: roselybittencourt@hotmail.com.

** Assistente Social, pós-graduada em Segurança e Medicina do Trabalho e Metodologia do Trabalho com Famílias, atua como Diretora de Proteção Social Básica, da Fundação de Ação Social, Prefeitura Municipal de Curitiba.E-mail: corres@uol.com.br.
} 
refering those individuals and families living in conditions of vulnerability and social risk sustained a vision of participation and performance of the leading families toward independence and emancipation. The aim of this paper is to analyze the work done with families in the "Family Project Curitiba" according to guidelines and provisions of the Social Assistance and relating systematizing cutting goals of different public policies. The method used for the lifting of the data is the documentary screening, with consultation of the Intersectoral Management Protocol, Plan of Government, rapporteurs and Institutional Assessment of the Family Project Curitiba. It was established for the Project Management Contract for the care of 7000 households between 2009-2012, tending goal of full compliance in the period. Project aims and positive results, both quantitative and qualitative, in the field of social protection for families, reducing social vulnerabilities, or in the field of management, with the extension of monitoring and controlling them.

Keywords: Methodology working with families. Family project Curitiba. Social protection. Social vulnerability.

\section{Introdução}

O movimento constituinte e o advento da Constituição da República Federativa do Brasil (1988) instauraram importantes mudanças, especialmente no avanço aos fundamentos para garantir os direitos do cidadão, por meio de políticas sociais fundadas inicialmente na Declaração Internacional dos Direitos Humanos (1948) celebrada em Genebra, Suíça, efetivando o homem como centro no universo.

A Assistência Social, acolhida pela Lei Orgânica da Assistência Social (BRASIL, 1993), integra a Política de Seguridade Social, em conjunto com a Previdência Social e Saúde, ganhando novos contornos quando a "questão assistência" torna-se um direito juridicamente constituído no Brasil.

A Política Nacional da Assistência Social - PNAS (BRASIL, 2004) foi concebida a partir da centralidade da família, superação de foco e descentralização dos serviços aos usuários nos territórios em áreas onde se concentram riscos, no sentido de atingir resultados efetivos no trabalho social. Assume o papel fundamental de emancipar famílias e funciona como vetor de articulação intersetorial com as políticas públicas de Saúde, Educação, Cultura, Esporte, Emprego e Habitação, para que ações integrais se configurem e mantenham o acesso e qualidade aos serviços destinados à família, seus membros e/ou indivíduos. 
A falta de efetividade da intervenção técnica na assistência social exige ressignificado frente ao sistema descentralizado e participativo, redimensionando o foco do trabalho para a família e para o território. A experiência historicamente acumulada com práticas segmentadas por faixa etária e/ou fenômenos sociais como trabalho infantil, violência doméstica, entre outros, exige intervenções que superem o isolamento de ações pontuais tanto na assistência social como na relação intersetorial com as demais políticas públicas.

A PNAS (BRASIL, 2004) possibilitou a transição entre a tradição caridade-favoritismo político, e reconduziu a assistência para um novo estágio, em que as ações estivessem sintonizadas com o direito social do cidadão, estimulando a articulação entre distribuição de renda, trabalho social e projetos de geração de renda protagonizados pelas famílias. ${ }^{1}$

O Sistema Único da Assistência Social (SUAS), ferramenta de gestão da PNAS constitui a regulação e organização, em todo o território nacional, da rede de serviços socioassistenciais e, tal qual a PNAS, NOB e SUAS, tem como foco prioritário a atenção extensa à família no território como base de organização (BRASIL, 2010).

Diante dos desafios supramencionados e, ao considerar os pressupostos éticos dos profissionais assistentes sociais, voltados à defesa dos direitos da cidadania, a Lei Orgânica da Assistência Social (LOAS) e a implementação do Sistema Único da Assistência Social (SUAS), como responsabilidade do Estado Direito do Cidadão, questiona-se para o presente estudo: como se estrutura uma metodologia de trabalho com famílias em situação de vulnerabilidade social?

Norteados por tal inquietação, partiu-se da experiência vivida no município de Curitiba, com o objetivo de analisar os processos de trabalho, aqui entendidos como as formas com que se organiza o trabalho, com famílias no "Projeto Família Curitibana". Seguindo diretrizes e preceitos da Assistência Social na construção de metodologias de trabalho coletivo, busca-se, ainda, sistematizar tais processos, relacionando-os com metas intersetoriais de diferentes políticas públicas, com a visão de participação e

\footnotetext{
${ }^{1}$ Ao implantar a Norma Operacional Básica - NOB (BRASIL, 1996), com novas reformas em 1997/1998, o Ministério da Saúde pretendeu fortalecer a gestão municipal do Serviço Único de Saúde (SUS), elevar os níveis de saúde e bem-estar da população, estimular a participação da comunidade na definição e acompanhamento da implantação das políticas do setor, transferindo recursos financeiros do Fundo Nacional de Saúde (FNS) para os Fundos Municipais (FM) de 700 Municípios brasileiros (1998), elevando-os à condição de gestores plenos do Sistema Municipal (SM).
} 
atuação protagonista das famílias, rumo à autonomia e emancipação. Ou seja, trata-se de uma estratégia de caracterização da abordagem técnica do trabalho com famílias, implementada pelo Projeto Família Curitibana, que prevê novos paradigmas no planejamento da política de assistência social integrada às demais políticas setoriais, estabelecendo um processo participativo que busca autonomia e emancipação familiar e comunitária.

O levantamento de dados é fundado na pesquisa documental, fonte primária que utiliza documentos de domínio público, realizada mediante argumentações de defesa de projetos, correntes de opinião, declarações, discursos oficiais, leis, entre outros. Para a presente pesquisa documental, foram utilizadas fontes escritas, como: protocolo do Projeto Família Curitibana, relatórios de gestão e regionais, plano de governo, entre outros, consolidando-se em informações que permitam às pesquisadoras, condições de análise do Projeto como metodologia de trabalho/intervenção. As fontes documentais podem ser encontradas na internet, em páginas especializadas da Prefeitura Municipal de Curitiba, nos arquivos da Fundação de Ação Social e em materiais de divulgação institucionais. $O$ tratamento dos dados, de caráter qualitativo, tem como matéria-prima o Projeto como proposta de governo, estabelecido por debate e construção coletiva de variados atores governamentais, consolidado em um sistema de definições e ações entre múltiplas forças, afetado e constituído por relações de poder.

A sistematização e construção de uma metodologia de trabalho do Projeto Família Curitibana, com início em 2009, demonstra que a Proteção Social Pública se faz por meio do conjunto das Políticas Sociais. Considerando a Proteção Social como dever do Estado e Direito do Cidadão, não exclui a responsabilidade da sociedade civil na realização de ações referentes à melhoria das condições de vida das famílias e do grau de vulnerabilidade, em uma gestão em rede.

As principais ações do Projeto Família Curitibana, em âmbito do Governo Municipal propõem um pacto intergestores das Políticas Públicas, propiciando debates nos diferentes níveis de gestão (Comitês) e em instâncias de controle social, especialmente, o Conselho de Assistência Social, a construção de indicadores objetivos e subjetivos, que correspondam ao monitoramento e avaliação do processo de intervenção dos técnicos, 
principalmente, mediado pela participação da família no processo de autonomia e emancipação própria.

\section{Considerações históricas sobre família}

De acordo com Straube (2009), a família se formou através dos tempos, em um ambiente propício à formação de um grupo, ao exercício de poder e por diferentes culturas. No entanto, atravessa turbulências em um mundo em constante mutação, contudo, é a organização mais valorizada, protegida e defendida na sociedade.

A família é natural e provém da essência biológica do homem e que se unindo a uma companheira geram prole, cujos laços familiares se dissolvem com o fim das necessidades dos filhos, sendo substituídos por outros laços de caráter afetivo, para os quais se não existissem a família se dissolveria (STRAUBE, 2009).

Rosseau admitiu que mesmo os laços familiares podem desaparecer quando não chegam a serem criados. Nesse sentido, o amor é algo implícito à natureza humana. LévyStrauss afirmou que a família supera a ligação consanguínea e resulta de uma união cultural por afinidade (apud STRAUBE, 2009).

A partir da instauração do Absolutismo e desenvolvimento das camadas burguesas a família se moderniza em novos moldes, e com o passar do tempo, mesmo o proletariado, explorado pela burguesia, adere a um novo modelo de família, embora questionado para ser vivido por todas as classes sociais, com inúmeras diferenças, apesar de muitas semelhanças entre seus membros (STRAUBE, 2009).

O modelo mais aceito é o que coloca pai, mãe e filhos, com funções distintas, podendo reunir mais indivíduos ao seu grupo. Anterior ao século XVIII, o poder era centrado na figura do pai, o qual estabelecia autoridade suprema, ficando mulher e filhos em patamar de inferioridade e obediência. No entanto, mediante a evolução de conceitos, o foco foi transferido à criança, recebendo a mãe um novo significado no papel de protetora e mantenedora da família, ficando o pai em segundo plano nesse novo cenário. Nesse novo ambiente, o papel do pai gradativamente foi perdendo o significado e foi substituído para um papel puramente econômico, de provedor (STRAUBE, 2009).

Após a Segunda Guerra Mundial, houve uma supervalorização no modelo tradicional de família. Ganha importância o papel da mãe, colocado acima do papel de 
mulher, agora como referência e suporte emocional (STRAUBE, 2009). Nesse novo modelo familiar, as relações existentes entre pais e filhos tornam-se complexas, exercendo relação direta entre sociedade-política, induzindo a família a aproximar-se do Estado para que juntos detivessem maior poder disciplinador de futuros cidadãos (STRAUBE, 2009).

Nesse processo, a família, progressivamente, passa a enfrentar crises que amalgamam diferentes regiões do país, permitindo uma nova remodelação na estrutura, conforme apontam os sociólogos Adorno e Horkheimer (1996). No entanto, embora a crise parecesse um perigo nessa nova sociedade, ela serve como impulso para que a família assuma nova postura na dinâmica social (STRAUBE, 2009).

Kaslow (2001, p. 40) cita nove tipos de composição familiar que pode ser considerada "família":

1. Família nuclear, incluindo duas gerações, com filhos biológicos;

2. Famílias extensas, incluindo três ou quatro gerações;

3. Famílias adotivas temporárias;

4. Famílias adotivas, que podem ser bi-raciais ou multiculturais;

5. Casais;

6. Famílias monoparentais, chefiadas por pais ou mãe;

7. Casais homossexuais com ou sem crianças;

8. Famílias reconstituídas depois do divórcio; e

9. Várias pessoas vivendo juntas, sem laços legais, mas com forte compromisso mútuo.

No contexto dos novos arranjos familiares observa-se que diminuíram as exigências de uniões formais e os papeis e funções de pai e mãe antes fortemente delimitados, hoje, obedecem à dinâmica da realidade de subsistência destes grupos em suprir necessidades básicas, e demais exigências que se constituem em condições dignas de qualidade de vida. Em sua relação com as condições materiais de vida, "ser pobre significa não dispor de meios para operar adequadamente no grupo social que pertence" (ROCHA, 2003, 10). Sendo assim, considera-se que estas pessoas e/ou famílias não apresentam condições objetivas e estruturais para acessar e permanecer na condição de cidadãos de direitos.

A família historicamente foi objeto de estudo, porém, resultando em materiais fragmentados, em que indivíduos portadores de problemas oriundos da própria vulnerabilidade, políticas mal formuladas e recursos mal distribuídos eram inseridos em 
programas relacionados no rol de faixa etária e/ou fenômenos relativos à violação de direitos, abandono, doenças mentais, drogadição, entre outros.

Como unidade e contextualizada no território, na atualidade, a família representa um desafio na atuação dos trabalhadores sociais nos diversos níveis político-socialpúblicos. As novas configurações ou arranjos atualmente definem a superação do foco nas estruturas nucleares, pois tais composições são decorrentes da convivência entre as pessoas, formas de sobrevivência, das relações no território e sua comunidade e sociedade mais ampla.

\section{Vulnerabilidade social, matrialicidade sociofamiliar, território}

A PNAS (BRASIL, 2004, p. 33) define como público-usuário da política cidadãos e grupos que se encontrem em situação de vulnerabilidade e riscos sociais, caracterizandoos pelo seguinte enunciado:

[...] famílias e indivíduos com perda e fragilidade de vínculos de afetividade, pertencimento e sociabilidade, ciclos de vida; identidades estigmatizadas em termos étnicos, cultural e sexual, desvantagem pessoal resultante de deficiências, exclusão pela pobreza e/ou no acesso às demais políticas públicas, uso de substâncias psicoativas, diferentes formas de violência advinda do núcleo familiar, grupos e indivíduos, inserção precária ou não inserção no mercado de trabalho formal e informal, estratégias e alternativas diferenciadas de sobrevivência que podem representar risco pessoal e social.

A vulnerabilidade social de grupos de famílias em territórios concentradores de riscos sociais está relacionada com a precária infraestrutura urbana, cuidados domésticos, relações interpessoais, vizinhança, valores, credos e formas de geração de renda, situações que, contrariamente ao que possa parecer, apresentam potencialidades possíveis de participação na identificação do diagnóstico e apresentação de formas de solução para os problemas, considerando-as protagonistas e demandando ações por parte do poder público para o fortalecimento de vínculos familiares e comunitários.

De acordo com o Centro de Estudos e Pesquisas de Administração Municipal Mestriner (2007, p. 23), Fundação Prefeito Faria Lima: 
partir da história, do quadro cotidiano e do universo cultural da população, na perspectiva de uma atenção globalizada. Por outro lado, articulando a descentralização e intersetorialidade, programas e projetos podem se integrar na aproximação aos interesses e necessidades reais da população, mobilizando estrategicamente, potencialidade e fortalezas pessoais, familiares e locais, fazendo-o de forma a instigar a participação, iniciativa e o empreendedorismo. Programas com famílias obedecem a recortes territoriais, possibilitam que se atinjam situações problemáticas similares e relevantes, de forma intersetorial e em parceria com a própria população, levando a resultados mais amplos e integrados, que causem impacto positivo nas condições gerais de vida das pessoas.

Yasbec (2009) comenta que a precariedade da vida é o primeiro fator que hierarquiza as famílias por setor censitário pela renda, escolaridade dos chefes de família e famílias mais jovens com maior número de dependentes e com possibilidade reprodutiva. O setor censitário, em microescala, nos territórios diferencia as famílias em graus de vulnerabilidade.

Nesse mesmo pensamento, Carvalho (2004, p. 17) cita que: “[...] território não é apenas [um] local de moradia e convivência, mas o lugar onde a família tem possibilidade de fazer sua vida e esta se realiza pelo que o território oferece ou não como sua condição social."

Koga (2003, p. 39) complementa: "a dimensão territorial traz elementos que permitem uma perspectiva de totalidade da questão social [...]". Consideram-se os aspectos das necessidades e as relações estabelecidas entre os sujeitos e seu cotidiano. Trabalhar nessa perspectiva permite entender as pessoas denominadas pobres como sujeitos.

O território diz respeito às condições objetivas e subjetivas da realidade de vida das famílias e das pessoas. Os processos sociais levam em conta as vulnerabilidades sociais que precisam ser superadas pelo sujeito, estado e sociedade por meio da Proteção Social.

A rede socioassistencial como parte desse contexto caracteriza-se por um conjunto integrado de iniciativas públicas e das organizações sociais que se apresenta como recurso estratégico na provisão de parte das soluções que contribuem para um resultado global das ações com famílias. Busca-se ainda um sistema de interação no qual a cooperação é mútua e recorrente, indicativas como potencialidades no processo de sobrevivência das famílias pobres. 


\section{Projeto Família Curitibana}

\section{Concepção do projeto}

O Projeto Família Curitibana teve início com o Contrato de Gestão, caracterizandose como ferramenta estratégica de gerenciamento do Plano de Governo à cidade de Curitiba (2009-2012).

Nos contratos de gestão estão sintetizados programas que se desdobram em projetos nas áreas de desenvolvimento econômico, ambiental, social e urbano, ficam sob a responsabilidade de uma Secretaria ou Órgão Municipal e Secretarias afins, corresponsáveis no que concerne aos produtos, tornando-se um marco de acompanhamento. No caso do Projeto Família Curitibana, as Secretarias parceiras são corresponsáveis pela gestão deste, concretizada por meio de Comitês Intersetoriais de Gestão, nos níveis Municipal, Regional e Local.

O documento "Diretrizes e Bases para o Contrato de Gestão" norteador do Contrato de Gestão é uma ferramenta de alinhamento organizacional com foco em resultados. $\mathrm{O}$ alinhamento refere-se à pactuação de objetivos e metas na concretização de programas e projetos, que define claramente as atribuições de gestão e execução destas, estabelece a metodologia de monitoramento e avaliação permanente, que ocorre quadrimestralmente e é realizada pela Unidade de Gestão do Plano de Governo. A unidade constitui-se de um Colegiado de Gestão formado por cinco Secretarias: Secretaria de Planejamento (SEPLAN), Instituto Municipal de Administração Pública (IMAP), Secretaria Municipal de Finanças (SMF), Secretaria de Governo Municipal (SGM) e Gabinete do Prefeito (GAP).

Contrato de Gestão, segundo Ribeiro (2009, p. 73) caracteriza-se por:

[...] um pacto para resultados. É firmado entre o dirigente de uma organização e os dirigentes de suas unidades administrativas, com o intuito de tornar mais eficiente, eficaz e efetiva a administração como um todo. O sucesso de sua utilização está vinculado a um conjunto de estratégias de atenção e correção do desempenho organizacional, responsáveis por movimentos que oxigenam e instigam reações favoráveis.

As estratégias do Plano de Governo (2009-2012) para alcançar tais metas foram traçadas em cinco grandes eixos de ação: morar, aprender, trabalhar, cuidar e viver. 0 
Projeto Família Curitibana integra o Programa Promoção e Assistência Social, o qual pertence ao eixo "cuidar".

Ziobro e Giacominni (2009) destacam para esse eixo a responsabilidade do município com a justiça e os direitos sociais, reconhecendo o potencial dos homens e mulheres que vivem em Curitiba. Ou seja, o potencial do capital social existente na cidade e em seus territórios. No entanto reconhecem que as condições dos moradores da cidade não é a mesma para todos.

[...] alguns precisam de apoio especial na busca desta condição de autonomia, o que implica superar estratégias meramente assistencialistas, substituindo-as por outras que reconheçam sua força de transformação da sociedade e sua capacidade de emancipação. Cada território da cidade, onde moram as pessoas, especialmente aquele sob o risco, deve ser conhecido em seus detalhes, originando, a partir daí, soluções efetivas (ZIOBRO; GIACOMINNI, 2009, p. 67$68)$.

Há um alinhamento dessa visão com o Plano Nacional de Assistência Social (PNAS) - (2004), o qual se apresenta como um dos objetivos da Assistência Social, o provimento por meio de serviços, programas, projetos e benefícios para famílias, pessoas e grupos que apresentem situação de vulnerabilidade ou risco social. Tal política prevê, para o alcance de seus objetivos, a integração junto às outras políticas setoriais, o conhecimento das desigualdades socioterritoriais para uma "intervenção que garanta o atendimento das necessidades básicas sociais e à universalização dos direitos" (BRASIL, 2004, p. 33).

O Contrato de Gestão não é mera formalidade, mas um conjunto de instrumentos que podem maximizar, por meio de uma organização estratégica, o atendimento às famílias em maior grau de vulnerabilidade, figurado pelo público preferencial do Projeto Família Curitibana.

\section{Estruturação do Projeto}

O Projeto Família Curitibana foi implantado em 2009 como uma estratégia de ação intersetorial e integrada entre políticas públicas governamentais, objetivando a proteção, desenvolvimento e promoção social de famílias que vivem em situação de vulnerabilidade social em Curitiba. 
A meta estabelecida no Plano de Governo é atender a 7.000 famílias identificadas em situação de maior grau de vulnerabilidade social, por meio do índice de Vulnerabilidade Social das Famílias - IVSF, no período de 2009 a 2012. Prevê-se, ainda, a melhoria da condição de vulnerabilidade na ordem de $70 \%$ das famílias inseridas no quadriênio, conforme se observa na tabela abaixo:

Tabela 1 - Indicadores e metas do Projeto Família Curitibana

\begin{tabular}{|c|c|c|c|c|c|c|}
\hline \multirow[b]{2}{*}{ INDICADORES } & \multicolumn{6}{|c|}{ META GERENCIAL } \\
\hline & Vo & 2009 & 2010 & 2011 & 2012 & $\begin{array}{c}\text { META } \\
\text { GESTÃO }\end{array}$ \\
\hline $\begin{array}{l}\text { Famílias atendidas com melhoria na } \\
\text { situação de vulnerabilidade social. }\end{array}$ & $0^{*}$ & $5 \%$ & $15 \%$ & $20 \%$ & $30 \%$ & $70 \%$ \\
\hline $\begin{array}{l}\text { Novas famílias com maior índice de } \\
\text { vulnerabilidade atendidas }\end{array}$ & $0 *$ & 1.000 & 1.500 & 2.000 & 2.500 & 7.000 \\
\hline $\begin{array}{l}\text { Famílias com maior índice de } \\
\text { vulnerabilidade acompanhadas. }\end{array}$ & $0 *$ & 1.000 & 2.500 & 4.500 & 7.000 & 7.000 \\
\hline
\end{tabular}

Fonte: FUNDAÇÃO DE AÇÃO SOCIAL (2010).

Em 2009, a meta anual foi superada com o atendimento a 1.049 famílias, e em 2010 o Projeto atendeu novas 1.500 famílias. A previsão para 2011 é o atendimento a 2.000 famílias e em 2012 para 2.500 famílias, contemplando os nove Núcleos Regionais da Administração Municipal - divisão administrativa do município de Curitiba. Do total das famílias incluídas em 2009, aproximadamente 75\% melhoraram o índice de vulnerabilidade social, principalmente nas seguintes variáveis: Qualificação Profissional/ocupação; Situação de domicílio; Número de cômodos da Unidade de Moradia; Grau de instrução; o que significa superação significativa da meta do primeiro ano, mas não garante sua permanência no ano subsequente - uma vez que a família permanece por dois anos no Projeto e este indicador já foi contabilizado no primeiro ano para as 1049 famílias de 2009.

Entre as Secretarias e Órgãos Municipais que fazem parte do Projeto estão: Fundação de Ação Social (FAS), responsável pela coordenação, Secretaria Municipal de Abastecimento (SMAB), Secretaria Municipal de Saúde (SMS), Secretaria Municipal de Educação (SME), Secretaria Municipal de Trabalho e Emprego (SMTE), Secretaria Municipal de Esporte e Lazer (SMEL), Fundação Cultural de Curitiba (FCC), Companhia de Habitação Popular de Curitiba (COHAB), Secretaria Municipal do Meio Ambiente (SMMA), 
que atuam em conjunto na garantia do acesso das famílias aos programas, projetos e ações do município. Como suporte à gestão intersetorial do Projeto estão: o Instituto Municipal de Administração Pública (IMAP), a Secretaria Municipal de Administração (SMAD), o Instituto de Pesquisa e Planejamento Urbano (IPPUC), a Secretaria de Governo Municipal (SGM) e a Secretaria Municipal do Planejamento (SEPLAN). Cada um dos atores municipais envolvidos pactua a realização de serviços e a disponibilização de produtos às famílias, conforme demonstrativo do quadro 1.

Cabe destaque que outros tantos produtos/serviços compõem este rol, envolvendo outros tantos responsáveis, com metas definidas para cada ano projetado. As metas estabelecidas são acompanhadas e, ao final do período, avaliadas pelos grupos de gestão.

O modelo de atuação do Projeto se dá em três instâncias de gestão intersetorial: municipal, regional e local, estruturadas em Comitês, com competências distintas, mas que se complementam num processo articulado de desenvolvimento das ações nos eixos de intervenção: Assistência Social, Segurança Alimentar e Nutricional, Educação, Saúde, Habitação, Meio Ambiente, Trabalho, Esporte e Lazer e Cultura, com intervenção direta de técnicos de referência das famílias dos órgãos setoriais competentes, tendo como premissa a dimensão educativa do trabalho social e o caráter emancipatório das famílias.

Quadro 1 - Produtos/serviços das Secretarias e órgãos municipais

\begin{tabular}{|c|c|c|}
\hline PRODUTOS & $\begin{array}{c}\text { ÓRGÃOS } \\
\text { RESPONS. }\end{array}$ & META 2010 \\
\hline Vagas nas escolas do 10 ao 5o ano do Ensino Fundamental & SME & $\begin{array}{c}100 \% \\
\text { demanda }\end{array}$ \\
\hline $\begin{array}{c}\text { Vagas prioritárias na educação infantil para as famílias inseridas no } \\
\text { Projeto. }\end{array}$ & SME & $\begin{array}{c}70 \% \\
\text { demanda }\end{array}$ \\
\hline Subsídio alimentar. & SMAB & $\begin{array}{c}100 \% \\
\text { demanda }\end{array}$ \\
\hline Adequação de moradias & COHAB & $\begin{array}{c}50 \% \\
\text { demanda }\end{array}$ \\
\hline Membros das famílias participantes em cursos de capacitação \\
profissional & FAS/DGTR & $\begin{array}{c}1.050 \\
\text { pessoas }\end{array}$ \\
\hline Famílias com acompanhamento familiar & FAS/DPSB & $\begin{array}{c}2.500 \\
\text { famílias }\end{array}$ \\
\hline
\end{tabular}

\footnotetext{
${ }^{2}$ SME - Secretaria Municipal de Educação; SMAB - Secretaria Municipal de Abastecimento; COHAB - Companhia de Habitação Popular de Curitiba; FAZ - Fundação de Ação Social; DGTR - Diretoria de Geração de Trabalho e Renda; DPSB - Diretoria de Proteção Social Básica; SMS - Secretaria Municipal de Saúde.
} 


\begin{tabular}{|c|c|c|}
\hline Encaminhamento para documentação civil & FAS/DPSB & $\begin{array}{c}100 \% \\
\text { demanda }\end{array}$ \\
\hline Benefícios socioassistenciais & FAS/DPSB & $\begin{array}{c}100 \% \\
\text { demanda }\end{array}$ \\
\hline Ações socioeducativas & FAS/DPSB & $\begin{array}{c}100 \% \\
\text { demanda }\end{array}$ \\
\hline Atendimento em saúde & SMS & $\begin{array}{r}100 \% \\
\text { demanda }\end{array}$ \\
\hline Novos CRAS & FAS & 1 unidade \\
\hline
\end{tabular}

Fonte: FUNDAÇÃO DE AÇÃO SOCIAL (2010).

\section{Comitês de gestão intersetorial}

O Projeto atua em três instâncias de Gestão, devidamente estruturadas sob a forma de Comitês, com competências distintas, que se complementam em um processo dinâmico e articulado de desenvolvimento, pautado em ações de caráter intersetorial, distribuídos em nove eixos de intervenção. Os Comitês subdividem-se em: Comitê Intersetorial Municipal, Comitê Intersetorial Regional e Comitê Intersetorial Local, cada qual com funções distintas entre si.

O Comitê Intersetorial Municipal tem como prioridade garantir a intersetorialidade e integração das ações nas três instâncias; planejar as ações estratégicas intersetoriais e acompanhar os resultados; integrar os dados dos diversos sistemas de informação das Secretarias e órgãos envolvidos, isto é, quando possível; elaborar relatórios analíticos a partir dos resultados obtidos para subsidiar o planejamento das políticas setoriais; desenvolver, acompanhar e zelar pela metodologia de execução e pelos instrumentos utilizados nos processos de trabalho (IVSF); Plano de Ação Intersetorial; Protocolo e o Sistema Informatizado; propor alternativas de solução de questões apontadas pelos Comitês Regionais, já trabalhadas nos Comitês Regionais e Locais; zelar pelo cumprimento das metas previstas no Contrato de Gestão; realizar a capacitação das equipes dos Comitês Regionais e Locais; apoiar a Coordenação Geral do Projeto; mapear e articular ações da Rede social existente no município; elaborar, divulgar e manter atualizado o Protocolo de Procedimentos; estruturar e manter atualizado o Sistema de Informações Gerenciais; cuidar/zelar da relação intersetorial, mantendo os participantes e agregando novos parceiros; realizar análises a partir dos relatórios, propondo critérios e soluções 
para o aprimoramento das ações intersetoriais, zelando pela utilização dos recursos disponíveis; elaborar relatórios quadrimestrais das ações setoriais constantes no Contrato de Gestão para compor o relatório geral que será apresentado ao Prefeito por meio da Unidade de Gestão, observando as cláusulas do contrato anual; apoiar a implantação e manutenção dos Comitês Regionais e Locais; realizar ações periódicas setoriais para planejar, informar, monitorar e avaliar as ações junto ao Projeto.

O Comitê Regional visa garantir a intersetorialidade e integração das ações nas instâncias Regional e Local; implantar e manter os Comitês Intersetoriais Regional e Locais; planejar as ações regionais e acompanhar os resultados das ações dos Comitês Locais; elaborar relatórios analíticos a partir dos resultados obtidos para subsidiar o planejamento das ações regionais; desenvolver, acompanhar e zelar pela metodologia de execução e pelos instrumentos utilizados nos processos de trabalho (IVSF; Plano de Ação Intersetorial; Protocolo e o Sistema Informatizado); propor alternativas de solução de questões apontadas e já trabalhadas nos Comitês Locais e repassar ao Comitê Intersetorial de Gestão aquelas sem solução na instância regional; zelar pelo cumprimento das metas previstas no Contrato de Gestão; mapear e articular ações com a Rede de atendimento regional e local; realizar relatórios quadrimestrais das ações setoriais constantes no Contrato de Gestão para compor o relatório geral que será apresentado ao Prefeito por meio da Unidade de Gestão; elaborar agenda intersetorial de ações socioeducativas; cuidar/zelar da relação intersetorial mantendo os participantes e agregando novos parceiros; realizar reuniões de divulgação, apoio, informações sobre o Projeto Família Curitibana para os Comitês Intersetoriais Locais; compartilhar por meio do sistema de comunicação intersetorial a criação de instrumentos de gestão, sugestões de capacitação, necessidades de avanços que favoreçam a fundamentação ou fortalecimento do projeto; acompanhar e monitorar os resultados das ações intersetoriais regional e locais; avaliar e articular junto ao Comitê Regional os planos de ação dos Comitês Locais; promover encontros periódicos com todos os Comitês Locais para desenvolver a comunicação, troca de experiências e aprendizados, visando a construção de uma identidade regional do Projeto Família Curitibana.

O Comitê Intersetorial Local busca garantir a intersetorialidade e integração das ações na instância Local; planejar as ações locais intersetoriais e acompanhar os 
resultados das ações junto às famílias e a todo território; realizar abordagem e acompanhamento das famílias; avaliar periodicamente o acompanhamento das famílias e os resultados do projeto; realizar abordagens, acompanhamento e avaliação das famílias do projeto ou o redirecionamento das ações, com elaboração de novo Plano de Ação e Termo de Compromisso; elaborar relatórios analíticos a partir dos resultados obtidos para subsidiar o planejamento das ações locais; utilizar a metodologia de execução e instrumentos criados e indicados para os processos de trabalho (IVSF; Plano de Ação Intersetorial; Protocolo de Fluxo e Procedimentos; Sistema Informatizado etc.); propor e/ou solicitar alternativas para questões apontadas e já trabalhadas no Comitê Local, repassando ao Comitê Regional aquelas sem solução nesta instância; zelar pelo cumprimento das metas previstas no Contrato de Gestão; participar das capacitações do Projeto e propor necessidades pelo grau de importância; mapear e articular ações com a Rede de atendimento regional e local; subsidiar informações para os relatórios quadrimestrais das ações locais constantes no Contrato de Gestão para compor o relatório regional, organizando e codificando as informações; elaborar e acompanhar agendas intersetoriais em especial para as ações socioeducativas; validar, divulgar e propor atualizações para o Protocolo de Procedimentos; alimentar e manter atualizado os dados constantes no Sistema de Informações do Projeto Família Curitibana; operacionalização do Plano de Ação territorial com o Comitê Regional e Local; estabelecimento e assinatura do termo de adesão junto às famílias que irão participar do projeto; elaborar e acompanhar Plano de Ação Intersetorial Familiar; manter atualizada a listagem de representantes locais das Secretarias e Órgãos participantes do Comitê local; realizar análises a partir dos relatórios e propor soluções para o aprimoramento das ações intersetoriais local; realizar reuniões de divulgação, apoio, informações sobre o Projeto Família Curitibana; compartilhar por meio do sistema de comunicação intersetorial a criação de instrumentos de gestão, sugestões de capacitação, necessidades de avanços que favoreçam a fundamentação ou o fortalecimento do projeto; acompanhar e monitorar os resultados das ações intersetoriais da regional e da rede local; monitorar e avaliar as ações intersetoriais com as famílias; cuidar/zelar da relação intersetorial, mantendo os participantes e agregando novos parceiros; articular, programar e realizar ações de agenda conjunta para o atendimento das famílias e Gestão do Projeto. 
Dentre as competências do conjunto de Secretarias/Órgãos corresponsáveis estão: delegar representantes para participar dos Comitês Intersetoriais nas três instâncias, manter a mesma pessoa participando das ações e atividades e responsabilizar-se por oficializar caso ocorra mudança; participar das reuniões e atividades propostas pelos Comitês; elaborar em conjunto com os Comitês agendas de reuniões e atividades intersetoriais; realizar em conjunto com os Comitês o Plano de Ação anual; acompanhar a participação de seus representantes nas atividades dos Comitês nas três instâncias (Municipal, Regional e Local); repassar os dados de atendimento aos responsáveis pela sistematização dos dados nos Comitês Intersetoriais - representante da FAS e SGM (Secretaria de Governo Municipal); realizar reuniões periódicas setoriais para planejar, informar, monitorar e avaliar as ações junto ao projeto; realizar relatórios quadrimestrais das ações setoriais constantes no Contrato de Gestão para compor o Relatório Geral a ser apresentado ao Prefeito, por meio da Unidade de Gestão; repassar informações que subsidiem critérios à expansão do número de famílias, zelando pela utilização dos recursos disponíveis; disponibilizar as possibilidades de ações socioeducativas para as famílias participantes; respeitar e apoiar as diretrizes do órgão coordenador do Projeto; construir ferramentas e instrumentos para monitoramento e avaliação das ações, que permitam manter atualizada mensalmente o número de atendimento, bem como a listagem das famílias atendidas (para produtos únicos ou contínuos e passíveis de sistematização).

A Secretaria de Governo Municipal (SGM), que atua como representante direto do prefeito no âmbito regional por meio da Administração Regional, tem como competência respaldar a responsabilidade de oficializar os Comitês Regionais e seus representantes; responsabilizar-se por atualizar os dados dos representantes das Secretarias, quando necessário; comunicar a todos os participantes a composição dos Comitês Regionais, para que estes informem suas respectivas Secretarias; realizar reuniões sistemáticas com as Secretarias participantes; elaborar em conjunto com o Comitê Intersetorial Regional uma agenda de reuniões e atividades; realizar em conjunto com o Comitê Intersetorial Regional um plano de ação anual; acompanhar a participação dos representantes nas reuniões e atividades do Comitê Regional; expandir a participação de todas as Secretarias nos Comitês Intersetoriais Locais, encontrando soluções diante das estruturas 
diferenciadas de cada uma (pessoal), unidades locais e intervenção individual ou comunitária; atuar como o principal articulador e apoiador na formação e sustentabilidade dos Comitês Locais - em conjunto com o Comitê Intersetorial Regional; participar do monitoramento e avaliação, por meio do acesso ao sistema de informações do Projeto Família Curitibana; avaliar e articular junto ao Comitê Regional os planos de ação dos Comitês Locais; realizar encontros periódicos, junto ao Comitê Intersetorial Regional com todos os Comitês Locais para promover a comunicação, troca de experiências e aprendizados, visando a construção de uma identidade regional e local do Projeto Família Curitibana; incluir o Projeto Família Curitibana em pautas das reuniões coordenadas pela Administração Regional junto às lideranças da comunidade, objetivando maior visibilidade a este.

O papel estratégico e articulador da SGM reitera a vontade política do governo municipal em efetivar tal projeto de forma intersetorial.

Inserção das famílias no Projeto por meio do Índice de Vulnerabilidade Social (IVSF)

A seleção e identificação de famílias para o Projeto é realizada por meio do IVSF (Índice de Vulnerabilidade Social), composto mediante informações do Cadúnico, do Ministério do Desenvolvimento Social e Combate à Fome. O Cadastro Único (Cadúnico) para Programas Sociais é um instrumento de identificação e caracterização socioeconômica das famílias brasileiras de baixa renda, a ser utilizado para a seleção de beneficiários e integração de programas sociais do Governo Federal, voltados ao atendimento desse público. Além de servir como referência aos diversos programas sociais de concessão de benefícios, permite que o município e os Estados conheçam melhor os riscos e vulnerabilidades aos quais sua população está exposta.

Ressalta-se, porém, que o Cadúnico não é um programa, não concede benefício, mas subsidia com informações diversos programas para a concessão de benefícios às famílias cadastradas. O Governo do Município de Curitiba possui um banco de dados cadastrais de 113.000 famílias em situação de vulnerabilidade social. Estas famílias encontram-se mapeadas (geoprocessadas no território municipal). Dentro desse grupo, 7000 famílias se encontram em alta vulnerabilidade e se constituem em META prioritária do Governo Municipal. 
Para a identificação do grau de vulnerabilidade social, o município de Curitiba criou o Índice de Vulnerabilidade Social das Famílias (IVSF) a partir do cruzamento de vulnerabilidades apontadas no Cadúnico. As informações selecionadas/cruzadas refletem as condições de vulnerabilidade da população como: risco na habitação, risco social (baixa renda, falta de qualificação para o trabalho, presença de idosos e pessoas com deficiência) e risco ao desenvolvimento da criança, adolescente e famílias. Cada indicador possui um peso de referência, que resulta em uma pontuação para verificar os níveis de vulnerabilidade, conforme Escala de Índice (Tabela 3).

Tabela 3 - Escala de índice de Vulnerabilidade

\begin{tabular}{cc}
\hline & ESCALA DO íNDICE \\
\hline 0 & Sem vulnerabilidade \\
$1-9$ & Baixa vulnerabilidade \\
$10-14$ & Média vulnerabilidade \\
$15-35$ & Alta vulnerabilidade
\end{tabular}

Fonte: FUNDAÇÃO DE AÇÃO SOCIAL (2010).

Para fins de participação no Projeto, são selecionadas famílias com maior grau de vulnerabilidade, especialmente, que apresentam nível entre 15-35.

Plano de ação: análise e diagnóstico intersetorial

Os instrumentos metodológicos do trabalho social com famílias devem ser pautados em um processo de reflexão sobre a situação de vida das famílias e suas prováveis condicionantes socioeconômicas e culturais, favorecendo a percepção da dimensão individual e coletiva da problemática vivenciada, a definição de estratégias e de projetos individuais e coletivos de superação da situação de vulnerabilidade social, com vistas ao efetivo usufruto dos direitos sociais e à melhoria da qualidade de vida da população (ANDRADE; MATIAS, 2008).

O Plano de Ação Intersetorial Familiar é um instrumento de planejamento, execução, acompanhamento e avaliação das ações desenvolvidas com as famílias participantes do Projeto Família Curitibana, contém a análise diagnóstica intersetorial, objetivos, estratégias e metas, considerar o perfil da família, a avaliação das potencialidades, vulnerabilidades e necessidades de cada família, visando estabelecer 
intervenções intersetoriais, incluindo os encaminhamentos necessários à rede de serviços e orientações socioeducativas ao enfrentamento das dificuldades.

A etapa subsidia a sensibilização para adesão ao Projeto, compatibilizando o diagnóstico intersetorial com o autodiagnóstico pela família para o reconhecimento das vulnerabilidades e potencialidades, despertando a possibilidade de novas perspectivas para a promoção e busca conjunta da melhoria da qualidade de vida.

O diagnóstico das famílias é apresentado em reunião ordinária ao Comitê Regional pelo Comitê Local para consolidar compromissos e favorecer acompanhamento. As reuniões ocorrem após a consolidação do diagnóstico e sempre que houver mudança significativa na situação da família.

\section{Pactuação: Plano Intersetorial}

O pacto consiste em uma negociação entre as partes, em que as atribuições possíveis, de realização e alcance, ficam determinadas. O compromisso e a corresponsabilidade são base do Projeto Família Curitibana, efetuados no âmbito famíliapolíticas públicas, por meio do Plano Intersetorial Familiar.

O pacto familiar é um momento em que os atores, compromissados com a proposta, atuam em conjunto para promover mudanças em um processo que envolve esforço e disponibilidade. O processamento dessa fase depende do grau de confiança que se estabelece entre as famílias e o Poder Público Municipal.

Nesse momento, há famílias que se percebem como protagonista de sua história, sentindo-se fortalecidas para promover mudanças significativas em suas vidas. A pactuação é um processo contínuo em que as famílias a cada período podem revisar seus compromissos e repactuarem, e o poder público municipal assume responsabilidades junto a elas, solidificando um trabalho em corresponsabilidade à promoção do processo de protagonismo familiar e mudança nos seus índices de vulnerabilidade.

A consciência de mudança e transformação, fase em que a família reconhece a superação de vulnerabilidades, leva a novos compromissos, ou seja, mudanças efetivadas podem e devem servir ao impulso e aprofundamento de novas mudanças. 


\section{Acompanhamento, ajustes e desligamento do Projeto}

Durante o período de permanência no Projeto, as ações realizadas com a família são monitoradas e discutidas pelo Comitê Local e com a própria família, de modo a identificar os avanços alcançados, metas ainda a superar, potencialidades a serem mobilizadas, realização dos compromissos assumidos, necessidade de novos encaminhamentos, redução ou não da vulnerabilidade, entre outros. Para que isto aconteça, de fato, o trabalho técnico é sistemático e, portanto, demanda tempo. As reuniões dos comitês locais, para monitoramento, ocorrem semanal ou quinzenalmente e o acompanhamento familiar pelo técnico de referência (representante do poder público) é "intensivo", isto é, ocorre de forma diária ou semanal, tanto individual quanto coletivo, a partir de um planejamento integrado e de acordo com a demanda familiar.

Após permanência de dois anos no Projeto, prazo limite estabelecido, a situação da família é avaliada pela própria família e Comitê Local, de modo a verificar se esta atingiu as condições mínimas de qualidade de vida, superando vulnerabilidades. No caso em que as condições mínimas de qualidade de vida não foram atingidas com a superação de suas vulnerabilidades será estabelecido conjuntamente a continuidade do projeto com intervenção intensiva do governo municipal por mais seis meses ou de acordo com a gestão do caso. O desligamento da família não implica a sua desvinculação às políticas públicas setoriais e seu atendimento contumaz nas unidades públicas referenciadas.

\section{Resultados}

Além dos resultados numéricos anteriormente pontuados, no gráfico abaixo podemos observar que a tendência aponta para o atingimento das metas pactuadas no Plano de Governo, pois em 2009 supera o propósito, equilibra em 2010 e 2011 (com meta redimensionada por questões estruturais), e não apresenta desvio de alinhamento para 2012. 
Gráfico 1 - Família com maior índice de vulnerabilidade acompanhadas ou monitoradas

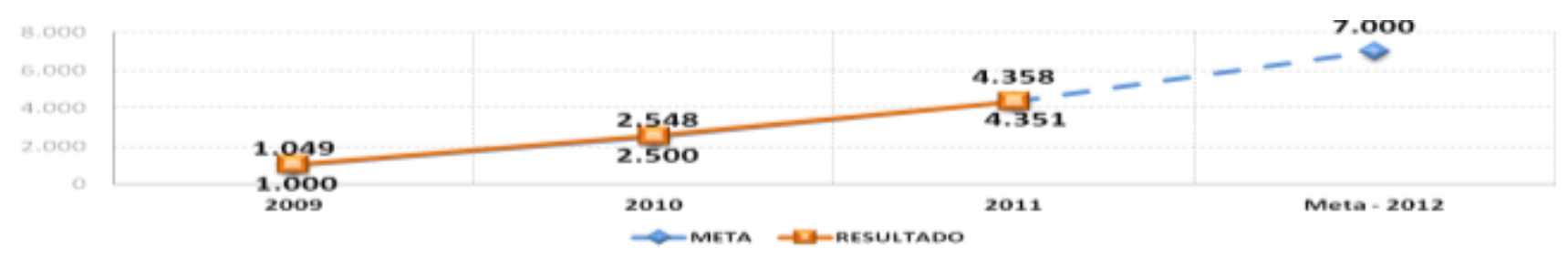

Fonte: FUNDAÇÃO DE AÇÃO SOCIAL, 2011b

Observa-se, ainda, no âmbito da Proteção Social que o Projeto Família Curitibana desde a sua implantação ao período em andamento, viabilizou: acesso aos serviços e à garantia de direitos; reflexo positivo a toda comunidade, não somente às famílias participantes; maior visibilidade e credibilidade dos serviços públicos à população beneficiária; maior proteção às famílias beneficiárias e sentimento de valorização por parte destas; identificação das famílias que por alguma situação/problema não acessavam as políticas públicas; valorização da comunidade com ações socioculturais.

No âmbito da gestão o Projeto, contribuiu para: ampliação do número de famílias cadastradas e manutenção dos Cadastros Únicos atualizados, possibilitando o controle, monitoramento e avaliação das famílias envolvidas; identificação das situações de vulnerabilidade das famílias; monitoramento e mensuração dos resultados obtidos pelos técnicos do Comitê Local; diagnóstico social compartilhado com levantamento de dados e identificação das demandas prioritárias para as Secretarias; fortalecimento de vínculos entre a família e o poder público; reconhecimento por parte das famílias de suas vulnerabilidades e a proposta de construção de alternativas, para acessar melhores condições de vida (protagonista); construção de um plano adequado à realidade de cada família, facilitando a aceitação às contrapartidas estabelecidas.

\section{Dificuldades e correções na gestão do Projeto}

O Projeto Família Curitibana, com todos os seus retornos positivos, não pode ser caracterizado pela perfeição. Muitas dificuldades foram encontradas, algumas foram passíveis de correção, outras ainda se efetivam como desafio. 
Dentre as dificuldades encontradas na execução do Projeto Família Curitibana, identificamos: rotatividade das famílias nas áreas priorizadas, que inviabilizam a sua permanência ou o adequado acompanhamento no Projeto; resistência de algumas famílias em aderir ao projeto e comprometer-se com o plano de ação, demandando intervenções variadas e energia do técnico de referência; problemas de segurança no território impedindo e/ou dificultando a intervenção profissional junto às famílias em determinados dias e horários; divergência das informações prestadas pelas famílias em relação aos cadastros das outras Secretarias; ausência de um sistema informatizado compartilhado entre Secretarias envolvidas, dos serviços disponibilizados e acessados pelas famílias, para o monitoramento adequado a estas; ausência de orçamento próprio ao projeto, o que levou à pactuação de produtos que concorrem para a sua efetivação com o restante da demanda da cidade, entre outros.

Cabe destaque a necessidade de correção na composição do IVSF que, atualmente, pautado em dados do Cadúnico, apresenta insuficiência de indicadores que apontem a complexidade de vulnerabilidade das famílias, isto é, não contempla indicadores subjetivos como: conflito familiar, conflito com a lei, uso de substâncias psicoativas etc., que influem de forma considerável no perfil de vulnerabilidade das famílias.

Ainda que o Projeto, de forma positiva, tenda a atingir a meta (numérica) proposta no Plano de Governo 2009-1012, se não (re) avaliada à luz da capacidade de gestão, para o próximo período de gestão (2013-2016), corre-se o risco de aportar em uma atuação periférica e superficial. O diferencial do Projeto é a atuação intersetorial e integrada, com acompanhamento sistemático e regular, que implica qualidade e tempo de atendimento que não são compatíveis com grandes quantificações.

\section{Considerações finais}

As dimensões de centralidade na família (territorização, intersetorialidade e protagonismo dos atores envolvidos) contemplam estratégias de gestão da família e estratégias coletivas de fortalecimento de vínculos familiares, de convivência com a vizinhança e com as organizações sociais existentes no território.

A criação do Projeto na cidade de Curitiba teve início na trajetória do engajamento de profissionais da FAS, SMAB, SEPLAN e IMAP, que, estimulados em transformar a 
realidade das famílias que vivem em situação de vulnerabilidade social, buscaram no Programa Chile Solidário - Projeto Puente compreensão técnica, política e social, para inspirar a construção dessa metodologia que, embasada na legislação brasileira, fundamenta-se na realidade curitibana.

O crédito ao caminho percorrido pelo Chile na atuação emancipatória das famílias, a Política da Assistência Social que preconiza a centralidade na família e território e as experiências exitosas sobre o trabalho em rede construído pela PMC garantiam a confiança profissional e política, capazes de tratar prioritariamente do Projeto Família Curitibana em Contrato de Gestão, assumido pela FAS como gestora, contando com mais onze Secretarias e Órgãos do Governo Municipal, como parceiros e corresponsáveis para modificar o IVSF da capital paranaense.

O atual modelo de atuação do Projeto Família Curitibana se define como estratégia de intervenção com as famílias com maior grau de vulnerabilidade do Município de Curitiba, estabelecendo como papel primordial a intersetorialidade das políticas e o protagonismo das famílias. A identificação dessas famílias, público-alvo de intervenção, por meio da experiência do Projeto e da ferramenta (IVSF) estabeleceu esta competência à Assistência Social na Gestão Municipal de Curitiba.

O Projeto Família Curitibana tem no seu marco de acompanhamento a objetividade de metas e produtos que perfazem a entrega ao trabalho coletivo, intersetorial e permanente dos profissionais que mobilizam as ações nos três níveis de Gestão Municipal, Regional e Local, fazendo com que chegue às famílias elencadas pelo IVSF a possibilidade de uma proposta de intervenção de caráter emancipatório. Em todas as esferas do governo municipal, estabelece-se a prioridade na atuação com famílias que se encontram em alto grau de vulnerabilidade social, com proposta metodológica construída com os trabalhadores sociais das diferentes políticas envolvidas e sistematizadas em um protocolo de procedimentos, para nortear, regulamentar, estabelecer fluxos de trabalho e mensurar o alcance do Projeto.

Os Comitês Intersetoriais que realizam a Gestão do trabalho enfrentam desafios cotidianamente, inerentes à realidade das famílias em situação de vulnerabilidade social e à realidade das políticas públicas brasileiras. Com a formatação de um método que atue coletivamente para transformar paradigmas, podem-se mobilizar estratégias significativas 
na mudança de atitude de cada um dos atores envolvidos, seja o poder público ou a família. O fortalecimento das famílias para buscar em si mesmas e na rede social as possibilidades de um novo trajeto no campo cidadania e direitos humanos constitui-se uma grande alternativa de intervenção social. A família vista com potencialidades e capacidade na solução de suas próprias vulnerabilidades se revela em um potencial de protagonismo na transformação de sua própria história familiar e comunitária. O acesso dessas famílias aos serviços públicos é fundamental na garantia de seus Direitos, contudo, a permanência e o acompanhamento sistemático facilita o processo de autonomia e emancipação dos sujeitos. Essa é a razão que subsidia no Projeto a efetivação do Poder Público na oferta, acesso e acompanhamento sistemático dessas famílias aos recursos como direito, por um período prioritário de dois anos.

A sistematização do Projeto Família Curitibana, especialmente na estruturação de uma metodologia capaz de atender ao emergencial e intervir para mudanças de longo prazo, por meio da atuação em corresponsabilidade, é o desafio assumido públicajuridicamente pela Prefeitura Municipal de Curitiba e pelos profissionais que gradativamente vão se engajando, compreendendo e dando condições para que cada ação intersetorial e coletiva garanta a solidificação não só de um Projeto, mas de uma nova forma de agir na linha da emancipação familiar e comunitária.

A conjugação de esforços dos diferentes atores que atuam no Projeto Família Curitibana efetiva princípios legais de "dever" do Estado e direito do cidadão para elevar a população a uma melhor condição de qualidade de vida na cidade de Curitiba. A experiência demonstra a necessidade de algumas correções, particularmente relativas à ampliação da composição dos indicadores do IVSF, de modo a garantir um diagnóstico mais preciso da vulnerabilidade das famílias e do estabelecimento de metas, que mantenham o desafio de atender à população com maior vulnerabilidade do município e garantam a necessária profundidade da intervenção profissional.

\section{Referências}

ADORNO, Theodor W; HORKHEIMER, Max. Teoria da semicultura. Trad. Newton Ramosde-Oliveira, Bruno Pucci e Cláudia B. M. de Abreu. In: Revista Educação e Sociedade de Ciência da Educação, a.XVII, nº 56, Campinas: Papirus, dez/1996, 388-411. Disponível em 
<http://planeta.clix.pt/Adorno> Acesso em 18 de outubro. 2010.

ANDRADE, P.; MATIAS, M. Trabalho social com famílias mo âmbito da Política de Assistência Social. Brasília, 2008.

CARVALHO, M. C. B. Trabalho com famílias. São Paulo: Instituto de Estudos Especiais da Pontifícia Universidade Católica de São Paulo, 2004.

BRASIL. Lei no. 8.742, de 7 de dezembro de 1993. Dispõe sobre a organização da Assistência Social e dá outras providências. Disponível em: <http://www.planalto.gov.br/ccivil_03/leis/L8742.htm>. Acesso em: 27 jun. 2010.

Norma Operacional Básica (NOB). 1996. Disponível em:

<http://www.mp.ba.gov.br/atuacao/cidadania/gesau/legislacao/texto/nob_sus_96.pdf>. Acesso em: 27 jun. 2010.

. Política Nacional da Assistência Social (PNAS). 2004. Disponível em:

<http://www.sesc.com.br/mesabrasil/doc/pnas.pdf>. Acesso em: 27 jun. 2010.

Sistema Único da Assistência Social (SUAS). Disponível em:

<http://www.mds.gov.br/assistenciasocial/suas>. Acesso em: 27 jun. 2010

MESTRINER, M. L. Programa bolsa família. São Paulo: Centro de Estudos e Pesquisas de Administração Municipal, 2007.

FUNDAÇÃO NACIONAL DE SAÚDE. Fundo Nacional de Saúde. Disponível em:

<http://www.funasa.gov.br/internet/index.asp>. Acesso em: 27 jun. 2010.

FUNDAÇÃO DE AÇÃO SOCIAL. Projeto família curitibana. Curitiba, 2010

FUNDAÇÃO DE AÇÃO SOCIAL. Protocolo de gestão dos centros de referência da assistência Social de Curitiba. Curitiba, 2009.

. Família curitibana: protocolo de gestão 2010-2011. Curitiba, 2011a.

. Relatórios de gestão: 2009-2011. Curitiba, 2011b.

. Relatórios técnicos: 2009-2011. Curitiba, 2011c.

KASLOW, F. W. Families and family psychology at the millenium. American Psychologist, Washington, v. 56, n. 1, p. 37-46, 2001.

KOGA, Dirce. Medidas de cidades: entre territórios de vida e territórios vividos. São Paulo, Cortez, 2003.

RIBEIRO, Angela de Andrade Kotzias. Contratos de gestão e inovação em administração municipal. (Cap. VI, p. 73-80). In: GIACOMINI, Carlos Homero. (org.). Gestão para resultados em Curitiba. A experiência de contratualização. I Edição. Instituto Municipal de Administração Pública - IMAP. Curitiba, 2009. 
ROCHA, S. Pobreza no Brasil: afinal, de que se trata? Rio de Janeiro: FGV, 2003.

STRAUBE, Kátia. A história da família e os desafios da pós-modernidade. [Artigo]. Especialização em metodologia do trabalho com famílias. ITECNE. Curitiba, 2009.

YASBEC, M. C. Base de Documento de referência Fundação de Ação Social, diretoria de Proteção Social Básica, 2009.

ZIOBRO, André Piekarz; GIACOMINI, Carlos Homero. Planos de campanha: peças-chaves em gestão para resultados (Cap. V, p. 57-71). In: GIACOMINI, Carlos Homero. (org.). Gestão para resultados em Curitiba. A experiência de contratualização. I Edição. Instituto Municipal de Administração Pública - IMAP. Curitiba, 2009. 